\title{
KAJIAN PENGELOLAAN FASILITAS PARKIR DI KAWASAN PENDIDIKAN : STUDI KASUS KAMPUS INSTITUT TEKNOLOGI BANDUNG
}

\author{
Shahnaz Nabila Fuady ${ }^{1}$, Puspita Dirgahayani ${ }^{2}$ \\ ${ }^{1}$ Perencanaan Wilayah dan Kota, Jurusan Infrastruktur dan Kewilayahan, ITERA \\ ${ }^{2}$ Perencanaan Wilayah dan Kota, SAPPK, ITB \\ ${ }^{1}$ Email : bellafuady@itera.ac.id
}

Disetujui (accepted): 15 Maret 2018

\begin{abstract}
ABSTRAK
Berkembangnya aktivitas di suatu kawasan pendidikan akan menimbulkan pergerakan yang semakin banyak juga di kawasan pendidikan tersebut. Kendaraan yang datang ke suatu area pendidikan pasti akan berhenti baik lama atau untuk beberapa waktu karena penggunanya akan melakukan kegiatan di dalam gedung, sehingga suatu pusat kegiatan pendidikan butuh lahan parkir yang memadai. Kampus ITB yang merupakan kawasan pendidikan di tengah Kota Bandung memiliki fasilitas parkir yang masik belum cukup menampung kebutuhan parkir yang ada saat ini, sehingga muncul on-street parking di jalan-jalan sekitar kampus. Pengelolaan parkir dilakukan dengan metode-metode berdasarkan preseden dan studi literatur yang disesuaikan juga dengan hasil analisis ketersediaan dan kebutuhan parkir di kampus ITB saat ini.
\end{abstract}

Kata Kunci : pengelolaan; parkir; Kampus ITB

\section{A. PENDAHULUAN}

Di kota-kota besar di Indonesia terjadi pertumbuhan kepemilikan kendaraan yang begitu pesat seiring dengan laju tingkat kesejahteraan masyarakatnya. Peningkatan kepemilikan kendaraan ini belum diimbangi dengan penyediaan prasarana transportasi yang memadai, sehingga menimbulkan permasalahan lalu lintas. Bandung sebagai salah satu kota besar di Indonesia tidak terlepas dari masalah ketersediaan lahan parkir. Menurut PP No. 43 Tahun 1993 tentang Prasarana dan Lalu Lintas Jalan, fasilitas parkir merupakan elemen yang sangat penting dalam transportasi. Lahan parkir harus selalu tersedia di area pusat kegiatan karena apabila tidak tersedia maka ruang jalan akan menjadi tempat parkir. Perkembangan aktivitas perguruan tinggi yang berada di pusat kota menimbulkan tarikan dan bangkitan pergerakan yang berpengaruh langsung pada kelancaran arus lalu lintas di jalan raya di sekitarnya. Tarikan dan bangkitan pergerakan tersebut berasal dari pergerakan kedalam perguruan tinggi maupun keluar perguruan tinggi. ITB sebagai perguruan tinggi favorit di Bandung memicu bangkitan dan tarikan pergerakan yang cukup besar dari dan ke arah kampus, sehingga kampus ITB butuh tempat parkir yang memadai. Kurangnya tempat parkir di ITB menyebabkan parkir kendaraan menjadi tidak teratur dan menggunakan jalan sebagai tempat parkir dan terjadi kemacetan arus lalu lintas. Tujuan yang ingin dicapai dalam penelitian ini yaitu untuk menyusun alternatif pengelolaan lahan parkir di kawasan Kampus ITB. 
Shahnaz Nabila Fuady dan Puspita Dirgahayani, Kajian Pengelolaan Fasilitas Parkir di Kawasan Pendidikan : Studi Kasus Kampus Institut Teknologi Bandung

\section{B. KAJIAN LITERATUR}

Menurut Direktorat Jendral Perhubungan Darat tahun 1996, pengertian parkir adalah keadaan tidak bergerak dari suatu kendaraan yang bersifat sementara atau dalam jangka waktu tertentu karena ditinggalkan oleh penggunanya. Menurut Kepmen No.66/1993 tentang Fasilitas Parkir untuk umum, fasilitas parkir harus memenuhi beberapa persyaratan yaitu menjamin keselamatan, kenyamanan, dan kelancaran lalu lintas, mudah dijangkau oleh pengguna jasa, apabila berupa gedung parkir, harus memenuhi persyaratan konstruksi sesuai persyaratan perundang-undangan, apabila berupa taman parkir, harus memiliki batas-batas tertentu, sirkulasi dan posisi parkir kendaraan yang dinyatakan dengan rambu lalu lintas atau marka serta parkir kendaran dilengkapi dengan fasilitas seperti pos petugas, lampu penerangan, dan pintu keluar dan masuk, serta diberi tanda berupa huruf atau angka. Metode - metode yang digunakan dalam pengelelolaan parkir adalah konsep penyediaan parkir, pembatasan parkir dan sistem zonasi. Hasil dari studi literatur dan preseden diperoleh hasil berupa sintesis beberapa alternatif solusi pengelolaan parkir di sebuah pusat kegiatan (Tabel 1):

Tabel 1. Alternatif pengelolaan parkir

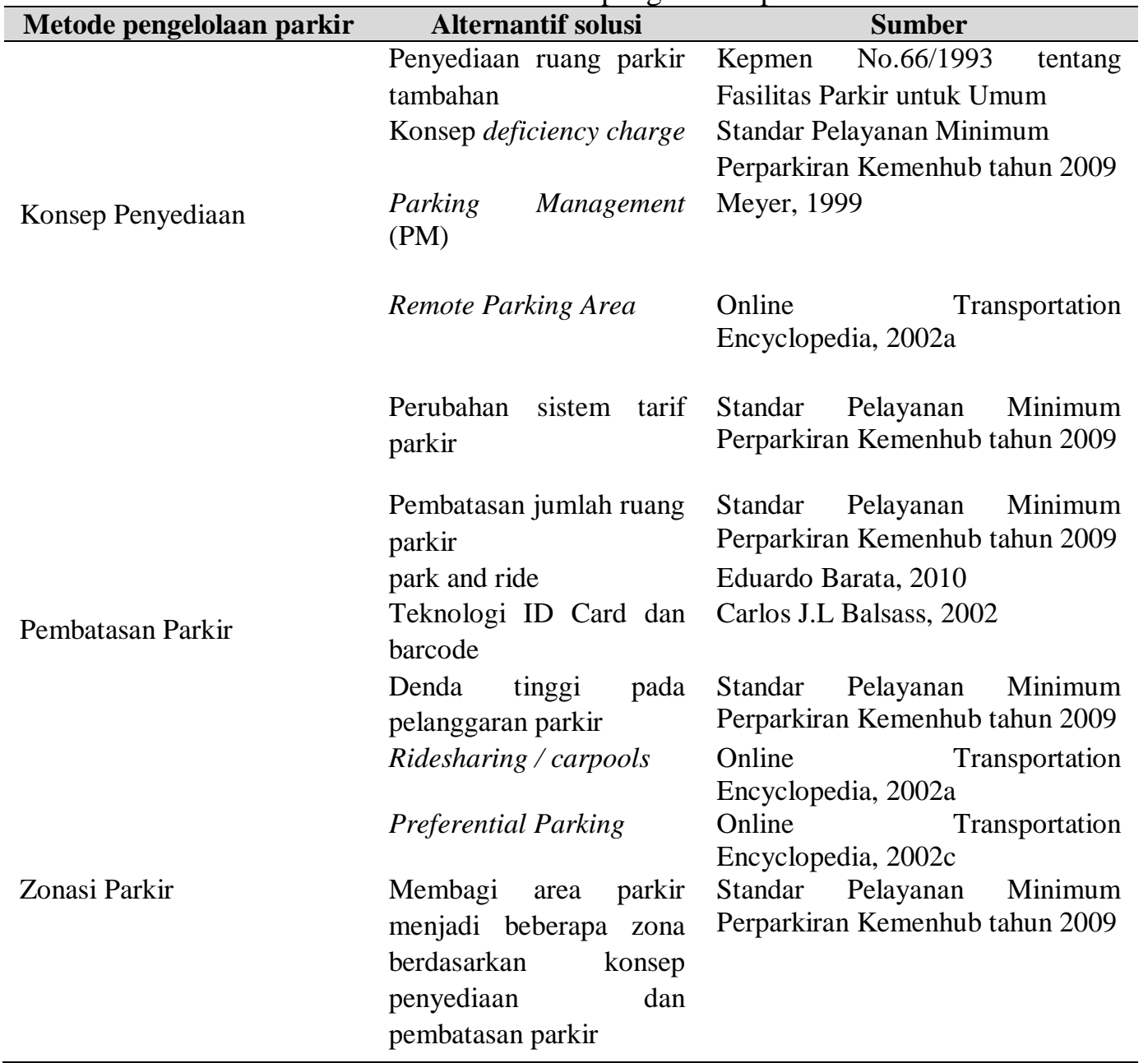

Sumber : analisis, 2015 


\section{METODE PENELITIAN}

Dalam penelitian ini dliakukan tiga tahapan pekerjaan, yang meliputi tahapan pengumpulan data, metode perolehan sampel dan analisis data. Pengumpulan data dilakukan dengan survey primer dan sekunder, sedangkan analisis dilakukan dengan analisis statistik dari data yang telah diperoleh. Survey yang dilakukan berupa survey primer dan survey sekunder. Survey primer yang dilakukan berupa survey volume parkir, survey latent demand, survey inventarisasi parkir, dan survey persepsi pengguna parkir. Survey sekunder juga dilakukan untuk memperoleh data lebih lengkap dari instansi terkait. Metode pertama menggunakan konsep peyediaan, dengan tujuan utama sebagai tempat parkir kendaraan karena pengendara melakukan aktivitas lain di sekitar lokasi parkir, maka penyediaan parkir harus tetap bisa menjamin lalu-lintas di sekitarnya berjalan dengan lancar. Metode kedua yaitu pembatasan parkir, elemen yang sering dan cukup efektif diterapkan dalam metode pembatasan parkir adalah dengan pengaturan tarif parkir. Metode ketiga yaitu zonasi parkir, yang dilakukan sejalan dengan 2 metode sebelumnya.

\section{PEMBAHASAN}

Dilakukan perhitungan untuk memperoleh sampel, terhadap total populasi sebanyak 20.558 yang terdiri dari mahasiswa, dosen, dan pegawai. Perhitungan sampel dilakukan dengan menggunakan rumus di bawah ini :

$$
n=\frac{z^{2} p(1-p) N}{z^{2} p(1-p)+e^{2}(N-1)}
$$

Dari hasil perhitungan diperoleh sampel sebanyak 137 orang. Penulis menyebarkan 150 lebar kuisioner dan membagi kampus menjadi 4 kuadran untuk mempermudah penyebaran kuisioner.

\section{Analisis Sediaan Parkir Kampus ITB}

Analisis sediaan parkir kampus dilakukan untuk mengetahui berapa jumlah kapasitas parkir yang tersedia saat ini dan dibandingkan denga rata-rata akumulasi parkir kendaraan perhari di 3 zona parkir utama di Kampus ITB, yaitu Zona Pakrir Barat, Zona Parkir Timur, dan Zona Parkir dalam ITB. Hasil analisis menunjukkan bahwa rata-rata akumulasi kendaraan perhari di Zona Parkir Barat adalah sebanyak 1.433 motor dari kapasitas 1500 lot parkir. Zona Parkir Timur sebanyak 1.355 motor dari kapasitas 850 lot parkir motor, dan 113 mobil dari kapasitas 65 parkir mobil. Sementara pada Zona Parkir dalam ITB, rata-rata akumulasi parkir perhari adalah sebanyak 1.682 mobil, dengan kapasitas 750 lot parkir mobil. Jadi, rata-rata akumulasi parkir kendaraan di 3 zona parkir tersebut sudah melebihi kapasitas yang ada saat ini paling banyak terpakai, dan kondisinya dibandingkan dengan kapasitas yang ada untuk saat ini. Analisis ini dilakukan di 3 Zona Parkir off-street yang ada di Kampus ITB. Analisis dilakukan dengan menghitung volume parkir kendaraan selama 24 jam, berdasarkan data kendaraan yang masuk dan keluar dari zona parkir, kemudian membandingkannya dengan kapasitas yang ada. 
Shahnaz Nabila Fuady dan Puspita Dirgahayani, Kajian Pengelolaan Fasilitas Parkir di Kawasan Pendidikan : Studi Kasus Kampus Institut Teknologi Bandung

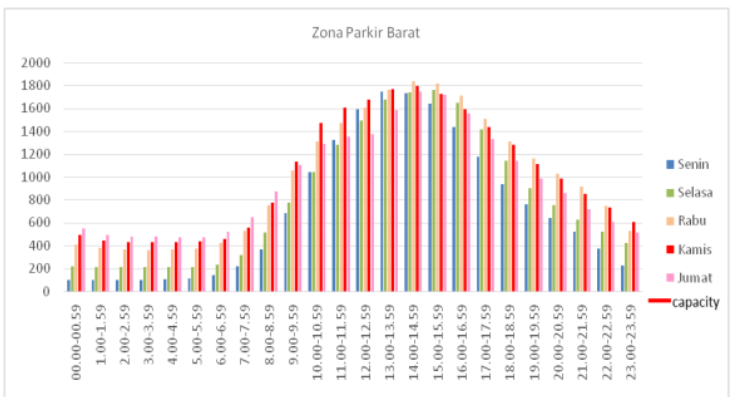

Gambar 1. Gap Analysis kapasitas dan kebutuhan parkir di zona parkir barat Sumber : hasil analisis 2015

Dapat diketahui bahwa jumlah lot parkir pada Zona Parkir Barat, yang paling banyak terisi setiap harinya berkisar antara pukul 11.00 hingga pukul 16.00. Dari grafik juga dapat kita lihat bahwa pada rentang waktu tesebut, kebutuhan parkir melebihi kapasitas yang ada saat ini yaitu sebanyak 1500 lot parkir untuk motor. Kebutuhan lot parkir terbanyak pada rentang waktu ini mencapai 1757 lot parkir.

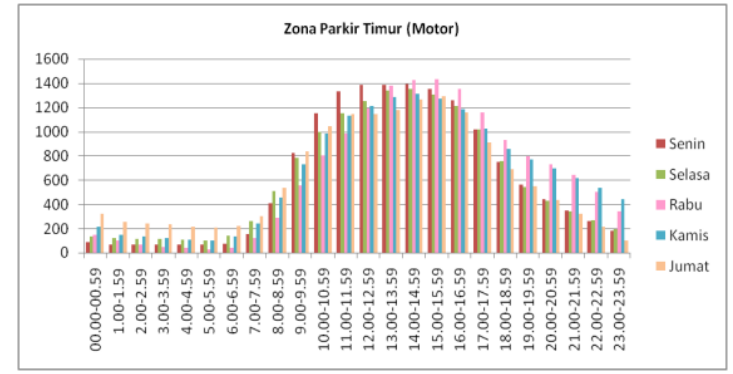

Gambar 2. Gap Analysis kapasitas dan kebutuhan parkir di zona parkir timur (motor) Sumber : hasil analisis 2015

Grafik di atas menunjukkan jumlah lot parkir motor pada Zona Parkir Timur, yang paling banyak terisi setiap harinya berkisar antara pukul 10.00 hingga pukul 17.00. Dari grafik juga dapat kita lihat bahwa pada rentang waktu tesebut, kebutuhan parkir melebihi kapasitas yang ada saat ini yaitu sebanyak 850 lot parkir untuk motor. Kebutuhan lot parkir terbanyak pada rentang waktu ini mencapai 1380 lot parkir.

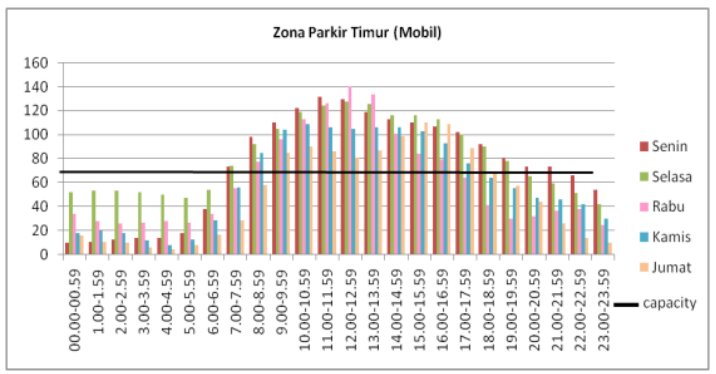

Gambar 3. Gap Analysis kapasitas dan kebutuhan parkir di zona parkir timur (mobil) Sumber : hasil analisis 2015

Dari grafik gap kapasitas dan kebutuhan parkir di atas dapat diketahui bahwa jumlah lot parkir mobil pada Zona Parkir Timur, yang paling banyak terisi setiap 
harinya berkisar antara pukul 09.00 hingga pukul 17.00. Dari grafik juga dapat kita lihat bahwa pada rentang waktu tesebut, kebutuhan parkir melebihi kapasitas yang ada saat ini yaitu sebanyak 65 lot parkir untuk mobil. Kebutuhan lot parkir terbanyak pada rentang waktu ini mencapai 140 lot parkir.

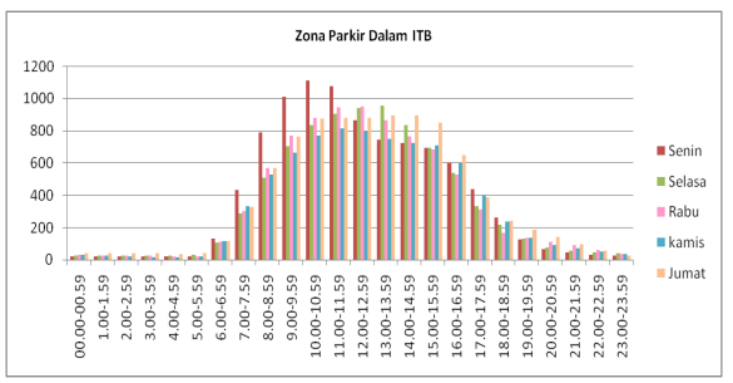

Gambar 4. Gap Analysis kapasitas dan kebutuhan parkir di zona parkir dalam ITB Sumber : hasil analisis 2015

Dari grafik gap kapasitas dan kebutuhan parkir di atas dapat diketahui bahwa jumlah lot parkir mobil pada Zona Parkir Dalam Kampus ITB (dosen/pegawai dan tamu), yang paling banyak terisi setiap harinya berkisar antara pukul 09.00 hingga pukul 15.00. Dari grafik juga dapat kita lihat bahwa pada rentang waktu tesebut, kebutuhan parkir melebihi kapasitas yang ada saat ini yaitu sebanyak 750 lot parkir untuk mobil. Kebutuhan lot parkir terbanyak pada rentang waktu ini mencapai 1112 lot parkir.

\section{Analisis Permintaan Parkir Kampus ITB}

Analisis ini dihitung dari akumulasi parkir maksimum dan jumlah mahasiswa yang tidak terlayani oleh sediaan fasilitas parkir eksisting. Namun, untuk menghitung akumulasi parkir maksimum, sebelumnya perlu diketahui jam sibuk kampus ITB terlebih dahulu. Jam sibuk kampus ITB perlu diketahui untuk menjadi acuan waktu survey area count yang selanjutnya digunakan untuk menghitung akumulasi parkir maksimum. Untuk mengetahui jam sibuk pada kampus ITB dilakukan mengidentifikasi jam sibuk berdasarkan data akumulasi parkir yang diperoleh dari ISS parking untuk 3 zona parkir off-street. Data tersebut diolah dari data keluar-masuk kendaraan dan data volume kendaraan pada hari Senin-Jumat (18 Mei 2015 - 22 Mei 2015). Berdasarkan akumulasi parkir terpadat, hari Senin merupakan hari terpadat, dengan total jumlah kendaraan yang masuk di 3 zona parkir sebanyak 4899 kendaraan, dan untuk total jumlah kendaraan yang keluar di 3 zona tersebut sebanyak 4076 kendaraan. Dapat diketahui bahwa jam sibuk fasilitas parkir kampus ITB untuk kendaraan masuk jatuh pada pukul 08.00 - 10.00. Sedangkan untuk kendaraan keluar, waktu terpadat jatuh pada pukul 16.00 - 18.00 .

\section{a. Proporsi Penggunaan Parkir oleh Dosen/Pegawai dan Tamu ITB}

Parkir di dalam kamups ITB memang hanya disediakan untuk dosen/pegawai saja. Namun, setiap hari selalu ada tamu yang memiliki kepentingan ke kampus ITB dan masuk, lalu menggunakan parkir di Zona Parkir Dalam ITB. Data diperoleh $15 \%$ dari pengguna parkir di dalam kampus adalah tamu. Lot parkir 
Shahnaz Nabila Fuady dan Puspita Dirgahayani, Kajian Pengelolaan Fasilitas Parkir di Kawasan Pendidikan : Studi Kasus Kampus Institut Teknologi Bandung

yang digunakan oleh tamu adalah lot parkir yang juga disediakan untuk tamu. Kapasitas parkir yang ada untuk dosen/pegawai saat ini masik kurang, ditambah lagi dengan kedatangan tamu yang juga menggunakan zona parkir dalam kampus ITB.

Tabel 2. Alternatif pengelolaan parkir

\begin{tabular}{|c|c|c|c|c|}
\hline \multirow[b]{2}{*}{ Hari } & \multirow{2}{*}{$\begin{array}{l}\text { Volume } \\
\text { parkir } \\
\text { dosen }\end{array}$} & \multirow{2}{*}{$\begin{array}{l}\text { Volume } \\
\text { parkir } \\
\text { tamu }\end{array}$} & \multicolumn{2}{|c|}{ Proporsi $(\%)$} \\
\hline & & & $\begin{array}{c}\text { Dosen/ } \\
\text { pegawai }\end{array}$ & Tamu \\
\hline Senin & 1838 & 126 & 94 & 6 \\
\hline Selasa & 1627 & 120 & 83 & 17 \\
\hline Rabu & 1785 & 104 & 91 & 9 \\
\hline Kamis & 1609 & 95 & 82 & 18 \\
\hline Jumat & 1551 & 102 & 79 & 23 \\
\hline Total & 8410 & 547 & 85 & 15 \\
\hline
\end{tabular}

Sumber : ISS Parking, 2015

\section{b. Durasi Parkir}

Setelah melakukan pengolahan data dari ISS Parking, dari data tersebut dapat diketahui rata-rata durasi parkir kendaraan yang parkir di kampus. Penggunaan parkir oleh mahasiswa untuk kegiatan kampus dan biasanya berlangsung selama 6 jam, untuk dosen selama 4 jam, dan untuk tamu selama 3 jam.

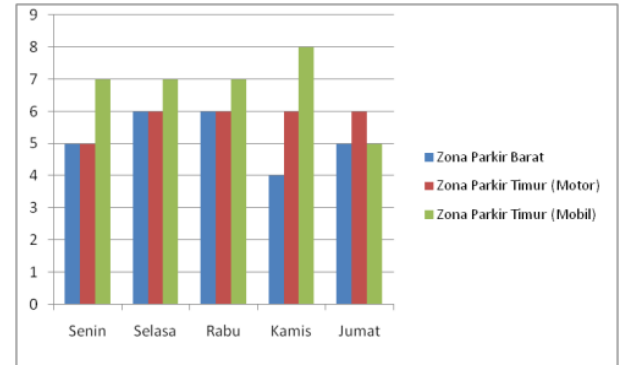

Durasi parkir mahasiswa

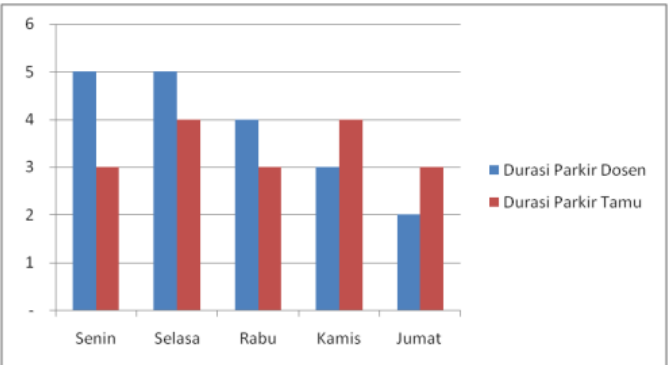

Durasi parkir dosen/pegawai dan tamu

Gambar 5. Durasi parkir mahasiswa, dosen/pegawai, dan tamu Sumber : hasil analisis 2015

\section{c. Latent Demand Terhadap Fasilitas Parkir di Kawasan Kampus ITB}

Dalam memberikan solusi terhadap permasalahan sediaan kapasitas parkir pada fasilitas parkir off-street yang ada di kampus, perlu juga melihat kebutuhan exsisting, yaitu dengan cara menganalisis akumulasi parkir maksimum, namun harus diketahui juga jumlah mahasiswa yang sebenarnya memiliki kendaraan pribadi namun tidak membawanya ke kampus, namun bisa jadi suatu saat membawa kendaraan ke kampus. Dengan kata lain, sebenarnya ada demand yang tidak terlayani oleh fasilitas parkir yang ada di kampus ITB saat ini. Demand tersebut disebut sebagai latent demand (berlebih). Berikut adalah tabel yang menunjukkan hal tersebut. 
Shahnaz Nabila Fuady dan Puspita Dirgahayani, Kajian Pengelolaan Fasilitas Parkir di Kawasan Pendidikan : Studi Kasus Kampus Institut Teknologi Bandung

Tabel 3. Latent demand parkir berdasarkan hasil kuisioner

\begin{tabular}{|l|c|c|}
\hline $\begin{array}{c}\text { Pengguna } \\
\text { Parkir }\end{array}$ & $\begin{array}{c}\text { Memiliki dan } \\
\text { membawa kendaraan (\%) }\end{array}$ & $\begin{array}{c}\text { Memiliki tapi } \\
\text { tidak membawa kendaraan (\%) }\end{array}$ \\
\hline Mahasiswa & 73 & 6 \\
\hline Dosen & 9 & 2 \\
\hline Pegawai & 7 & 3 \\
\hline
\end{tabular}

Sumber : hasil analisis tahun 2015

Dari 150 responden yang diberikan pertanyaan, $73 \%$ dari responden mahasiswa tersebut memiliki dan membawa kendaraan pribadinya ke kampus. Sedangkan yang memiliki tapi tidak membawa kendaraan pribadi ke kampus hanya sebanyak $6 \%$ saja, namun berkemungkinan akan membawa kendaraannya ke kampus. Zona parkir dalam kampus memiliki latend demand sebanyak 5\% dari dosen dan pegawai yang memiliki kendaraan pribadi namun tidak membawa kendaraan ke kampus. Latent demand untuk zona parkir dalam kampus dihitung juga dengan ditambah dari proporsi kedatangan tamu ke Kampus ITB, yaitu sebanyak 15\% dari total penggunaan parkir. Dari data kepemilikan Kartu Identitas Pegawai (KIP) baik untuk dosen maupun pegawai, dapat diketahui bahwa jumlah dosen/pegawai yang memiliki kendaraan pribadi adalah sebanyak 2686 orang, di mana jumlah populasi dosen/pegawai adalah sebanyak 2662 orang. Jumlah kepemilikan KIP lebih banyak dibanding dengan populasi dosen/pegawai. Sehingga setelah dihitung, untuk dosen/pegawai, latent demand sebanyak $5 \%$. Jadi latend demand zona parkir dalam kampus ITB adalah sebanyak 20\%.

\section{Analisis Hubungan Antara Preferensi Responden dalam Memilih Parkir Dengan Variabel Layanan}

Pada tahapan ini dilakukan analisis korelasi antara variabel keputusan responden dalam memilih parkir dengan variabel layanan yang antara lain terdiri dari variabel luas parkir, tarif parkir, keamanan parkir, kenyamanan, kemudahan akses parkir, kelengkapan fasilitas parkir, dan ketersediaan lot parkir. Analisis dilakukan setelah sebelumnya dilakukan survey kuesioner terhadap responden baik yang menggunakan parkir di lingkungan dalam kampus ITB maupun di luar kampus ITB.

Tabel 4. Korelasi antar variabel layanan parkir dalam ITB

\begin{tabular}{|l|c|c|}
\hline \multicolumn{1}{|c|}{ Variabel } & Chi Square Hitung & Chi Square Tabel \\
\hline Luas Parkir & 3,302 & 7,7794 \\
\hline Tarif Parkir & 2,00 & 6,2513 \\
\hline Keamanan & 4,317 & 7,7794 \\
\hline Kenyamanan & 9,412 & 7,7794 \\
\hline Kemudahan Akses & 6,837 & 6,2513 \\
\hline Kelengkapan Fasilitas & 0,364 & 6,2513 \\
\hline Ketersediaan Lot Parkir & 4,727 & 4,6051 \\
\hline
\end{tabular}

Sumber : hasil analisis tahun 2015 
Shahnaz Nabila Fuady dan Puspita Dirgahayani, Kajian Pengelolaan Fasilitas Parkir di Kawasan Pendidikan : Studi Kasus Kampus Institut Teknologi Bandung

Dari tabel diatas terlihat bahwa variabel kenyamanan, kemudahan akses dari lokasi parkir menuju tempat aktifitas, serta ketersediaan lot parkir memiliki nilai chi-square hitung yang lebih tinggi dari chi-square tabel, dengan demikian berdasarkan hasil survey dan analisis dapat disimpulkan bahwa variabel-variabel tersebut merupakan faktor yang paling mempengaruhi keputusan responden dalam memilih untuk parkir di lingkungan dalam kampus ITB.

Tabel 5. Korelasi antar variabel layanan parkir luar ITB

\begin{tabular}{|l|c|c|}
\hline \multicolumn{1}{|c|}{ Variabel } & Chi Square Hitung & Chi Square Tabel \\
\hline Luas Parkir & 8,449 & 7,7794 \\
\hline Tarif Parkir & 2,126 & 6,2513 \\
\hline Keamanan & 6,544 & 6,2513 \\
\hline Kenyamanan & 0,677 & 4,6051 \\
\hline Kemudahan Akses & 3,263 & 6,2513 \\
\hline Kelengkapan Fasilitas & 3,962 & 6,2513 \\
\hline Ketersediaan Lot Parkir & 5,236 & 4,6051 \\
\hline
\end{tabular}

Sumber : hasil analisis tahun 2015

Berbeda dengan responden pengguna parkir di lingkungan dalam ITB, berdasarkan hasil survey dan analisis korelasi antar variabel pemilihan keputusan untuk parkir dengan variabel-variabel penentunya, didapat bahwa variabel luas parkir, keamanan parkir, dan ketersediaan lot parkir memliiki chi-square hitung yang lebih besar dari chi-square tabel sehingga variabel tersebut menjadi faktor penentu dalam responden menentukan pilihan untuk membawa kendaraan dan parkir di sekitar kampus ITB namun di kawasan luar kampus.

\section{Alternatif Solusi Pengelolaan Parkir Berdasarkan Persepsi Pengguna \\ Parkir}

Dari hasil proses analisis yang telah dilakukan oleh penulis pada hasil kuesioner terhadap persepsi pengguna parkir ITB, dapat dirumuskan beberapa solusi sebagai alternatif pengelolaan parkir untuk kampus ITB.

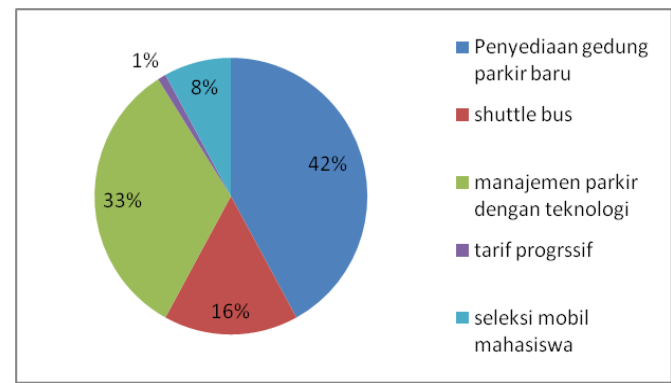

Gambar 6. Alternatif pengelolaan parkir menurut responden mahasiswa Sumber : hasil analisis 2015

Hasil diperoleh sebanyak $42 \%$ responden mahasiswa menginginkan ada penyediaan fasilitias parkir baru serupa gedung parkir sebagai tambahan untuk area parkir yang ada saat ini. Berikutnya, sebanyak 33\% responden menginginkan 
ada pengelolaan parkir berupa manajemen parkir dengan menggunakan teknologi. Sebanyak $16 \%$ responden menginginkan pengelolaan parkir berupa pengadaan shuttle bus dengan beberapa titik halte yang tersebar di sekitar kampus pada radius tertentu. Dapat disimpulkan bahwa pengelolaan parkir yang paling diharapkan oleh responden mahasiswa adalah berupa penyediaan fasilitas parkir tambahan berupa gedung parkir baru.

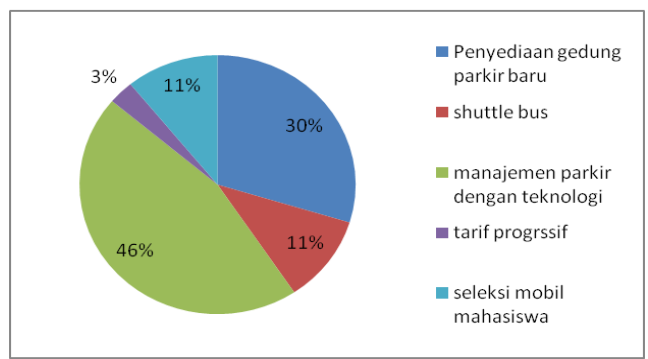

Gambar 7. Alternatif pengelolaan parkir menurut responden dosen dan pegawai Sumber : hasil analisis 2015

Dari grafik di atas juga dapat kita lihat juga bahwa sebanyak $46 \%$ responden dosen dan pegawai menginginkan adanya manajemen parkir dengan menggunakan teknologi smart parking. Dan sebanyak $30 \%$ responden mengingkan adanya penyediaan gedung parkir baru sebagai tambahan kapasitas yang ada saat ini. Lalu sebanyak $11 \%$ mengingkan adanya pengelolaan parkir dengan penyediaan shutle bus. Dapat disimpulkan bahwa pengelolaan parkir yang diharapkan oleh responden dosen dan pegawai adalah berupa pengelolaan parkir dengan penggunaan teknologi dalam sistem manajemen parkir kampus.

\section{PENUTUP}

\section{a. Kesimpulan}

Berdasarkan keluaran sasaran pertama dan berdasarkan hasil analisis, diketahui bahwa memang kebutuhan parkir saat ini melebihi kapasitas yang ada. Karena keterbatasan lahan yang ada baik di lingkungan kampus maupun sekitarnya, maka alternatif solusi pengelolaan fasilitas parkir yang paling tepat untuk ITB adalah dengan metode pembatasan parkir, dengan menggunakan elemen tarif dan manjemen parkir dengan menggunakan teknologi smart parking system. Hal ini dirasa lebih efektif daripada penyediaan fasilitas parkir tambahan, penyediaan fasilitas parkir tambahan hanya akan berupa solusi jangka pendek saja karena akan menimbulkan bangkitan pergerakan yang lebih banyak karena pengguna akan lebih mudah mendapatkan tempat parkir. Dengan menerapkan pembatasan parkir, maka diharapkan akan mengurangi tingkat penggunaan kendaraan pribadi dari dan ke arah kampus, juga akan mengurangi demand akan tempat parkir di kampus ITB.

b. Rekomendasi

1. Pembatasan parkir dengan menaikkan tarif parkir untuk mahasiswa, atau merubah sistem tarif flat yang selama ini berlaku menjadi sistem tarif 
Shahnaz Nabila Fuady dan Puspita Dirgahayani, Kajian Pengelolaan Fasilitas Parkir di Kawasan Pendidikan : Studi Kasus Kampus Institut Teknologi Bandung

progresif untuk mengurangi tingkat penggunaan kendaraan pribadi ke kampus oleh mahasiswa. Selain itu, direkomendasikan untuk memberlakukan tarif untuk parkir tamu yang masuk ke zona parkir dalam kampus ITB, sehingga diharapkan latent demand yang ada dari tamu yang setiap hari datang ke kampus dapat dikurangi.

2. Pembatasan parkir dengan manajemen parkir menggunakan teknologi parkir untuk memperketat sistem parkir untuk Zona Parkir Dalam ITB. Penulis merekomendasikan penggunaan teknologi parkir menggunakan teknologi barcode yang dapat mengkonfirmasi kedatangan tamu yang datang ke gedung gedung yang ada di dalam kampus, sehingga diharapkan teknologi tersebut dapat mengidentifikasi pengguna parkir yang akan masuk ke dalam Zona Parkir Dalam ITB.

3. Inovasi teknologi manajemen parkir dengan menggunakan Id Card yang teintegrasi dengan sistem absensi kehadiran dosen dan pegawai di masingmasing sekolah/fakultas. Dengan sistem ini, diharapkan kegiatan pengguna parkir terutama dosen dan pegawai akan lebih efisien dan lebih terkontrol.

\section{DAFTAR PUSTAKA}

Abubakar, I. 1998. Pedoman Perencanaan dan Pengoperasian Fasilitas Parkir, Direktorat Jenderal Perhubungan Darat Departemen Perhubungan. Jakarta.

Aoun, Alisar. Reducing parking demand and traffic congestion at the American University of Beirut. Transport Policy 25 (2013) 52-60. American University of Beirut, Beirut, Lebanon.

Balsas, Carlos J.L. Sustainable transportation planning on college campuses. Transport Policy 10 (2003) 35-49. University of Massachusetts, Hills North, Amherst, MA 01003, USA.

Eriyanto, 2007. Teknik Sampling : Analisis Opini Publik. Yogyakarta : LKIS.

Ferguson, Eric. 2006. Travel Demand Management and Public Policy. Inggris : Ashgate Publishing Ltd.

Hobbs, F. D. (1995) Perencanaan dan Teknik Lalu Lintas, Edisi Kedua, Gadjah Mada University Press, Yogyakarta.

John D. Edwards, Jr. And Institute of Transportastion Engineers. 1992. Transportation Planning Handbook. USA: Prentice-Hall,Inc.

Litman, T., Mobility Management As A Traffic Safety Strategy

Matsumoto, S., 1998, "Urban Transportation Options for Enhanced Accessibility and Sustainability in Indonesia", Simposium I FSTPT Bandung 3 Desember 1998, Intitut Teknologi Bandung, Bandung.

Meyer, Michael D dan Miler, Eric J. 1971. Urban Transportation Planning: A Decision-Oriented Approach. McGraw-Hill Higher Education.

Online Transportation Encyclopedia, 2002a, Parking Management , http://www.vtpi.org/tdm/tdm28.htm Diakses pada 20 Mei 2015

Online Transportation Encyclopedia, 2002b, Campus Transport Reduction, http://www.vtpi.org/tdm/tdm5.htm Diakses pada 20 Mei 2015 
Shahnaz Nabila Fuady dan Puspita Dirgahayani, Kajian Pengelolaan Fasilitas Parkir di Kawasan Pendidikan : Studi Kasus Kampus Institut Teknologi Bandung

Online Transportation Encyclopedia, 2002c, HOV Priority, http://www.vtpi.org/tdm/tdm19.htm Diakses pada 20 Mei 2015

Online Transportation Encyclopedia, 2002d, Parking Pricing http://www.vtpi.org/tdm/tdm26.htm Diakses pada 20 Mei 2015

Online Transportation Encyclopedia, 2002e, Parking Solution http://www.vtpi.org/tdm/tdm72.htm Diakses pada 20 Mei 2015

Oppenlender, J.C. 1976. Manual of Traffic Engineering Studies, Institute of Transportation Engineering Washington DC.

Setiawan, R., 2003a, Survey Volume Lalu Lintas 15 jam (6 Mei 2003), Laboratorium Teknik Lalulintas Universitas Kristen Petra, Surabaya.

Tamin, Ofyar Z. 2008. Perencanaan, Permodelan, dan Rekayasa Transportasi. Bandung: Penerbit ITB.

Tanariboon, Yordphol. (1992). An Overtime and Future Direction of TDM in Asian Metropolises. Regional Development Dialogue vol.13 no.3

Warpani, S.Ir. 1990. Rekayasa Lalu Lintas. Penerbit Bharata Karya Aksara ; Jakarta.

Wells, G.R., 1989, Traffic Engineering Introduction, Griffin, London.Pelabuhan Tanjung Pandan untuk Mendukung Ekspor CPO di Kabupaten Belitung. Institut Tekhnologi Bandung. Bandung 